\title{
Geoethics and Professionalism: The Responsible Conduct of Scientists
}

\author{
DAVID W. MOGK* \\ Montana State University \\ mogk@montana.edu
}

\begin{abstract}
The primary focus of geoethics has traditionally been on the responsible conduct of science: issues such as plagiarism, fabrication or falsification of data, and topics related to the doing of science. Equally as important to the success of the scientific enterprise are the personal attributes required of being a scientist and the responsible conduct of scientists in their personal interactions with colleagues and the public. In this contribution, numerous aspects of professionalism are addressed, which encompass behaviors and attitudes that impact the ability of scientists to do their work in the social environment of the workplace and with the public. Principles of professionalism have their foundations in concepts related to power, trust, respect, and responsibility. These are topics that are typically not directly addressed in day-to-day workplace communications or in classrooms, but they are essential in providing a safe, inclusive and productive work environment. Administrators, faculty, staff, students, managers and co-workers may encounter all manner of interpersonal conflicts that may affect the safety and productivity of their work environment. In particular, recent revelations about instances of sexual harassment and bullying in the geoscience workplace are of immediate concern and dictate that there must be changes in the geoscience work culture. Know how to recognize the signs of potential trouble, intervene early to prevent a bad situation, know the rules, and have a plan in place about how to respond to and mitigate impacts of unprofessional behaviors.
\end{abstract}

\section{INTRODUCTION}

$\mathrm{P}$ rofessionalism refers to the attitudes and behaviors that dictate the "climate" of the work environment through the many types of interpersonal relations between managers, colleagues, students and the public. The norms and standards established for these interpersonal relations have direct impact on the ability of scientists to do their work and for science to progress. In day to day practice, it is often the case that very little is said or acknowledged about the social environment in which we work, and lack of attention to interpersonal conflicts can lead to dysfunction in the workplace, exposure to civil liability, or even criminal prosecution. Everyone has a right to a safe, inclusive, supportive, and productive work environment. Professionalism addresses these fundamental rights. Professionalism is built on concepts and principles such as power, trust, respect, responsibility, and justice that define the foundations for healthy professional relations.

An awareness of these concepts provides a vehicle for self-reflection and institutional assessment: are you and your colleagues doing all you can to meet the highest standards of professional behaviors? Start the conversation in your workplace! Be proactive!

The purpose of this contribution is to help geoscientists be cognizant of established standards and norms of professional behavior, recognize unprofessional behaviors as they emerge, prevent these issues from having destructive and irreversible consequences, and have the tools to act and mitigate to resolve these issues. Continued education about professionalism in the classroom for students, and in professional development programs for 
working geoscientists, is needed for the longterm health of our profession.

\section{PRINCIPLES OF PROFESSIONALISM}

It's all about power. In any social structure or work environment there is inevitably a hierarchical, asymmetric power structure that involves leaders and how they interact with subordinates that presents great potential for unethical behaviors. Judicious use of power can support, enable and inspire. However, inappropriate use of power can lead to coercion, manipulation, intimidation, retribution, or denigration of individuals. It is worthwhile to reflect on the power structures in your work environment, where does power reside and how is it adjudicated? And in your personal interactions with peers and subordinates, are you aware of your power over others, and is this power used to enhance and enable or to erect barriers (whether deliberate or not) to the work of others?

An important corollary of power is the concept of trust. The many dimensions of trust are realized in interpersonal relations between coworkers as part of the scientific enterprise, and with the larger civic community. "The scientific enterprise is built on a foundation of trust. Society trusts that scientific research results are an honest and accurate reflection of a researcher's work. Researchers equally trust that their colleagues have gathered data carefully, have used appropriate analytic and statistical techniques, have reported their results accurately, and have treated the work of other researchers with respect" (National Academy of Sciences, 2009). Resnik (2011a) identified many key aspects of trust among individuals: relationships between or among people; between individuals and groups or the profession; to facilitate cooperative social interactions; as an expression of shared expectations of behavior; to enable risk taking; the expectation of appropriate use of skills and sound judgement; an expectation of competence, experience and good will; adherence to ethical and legal duties; and an obligation to do what is expected. Trust in scientific research is closely aligned with responsible conduct of research (National Academy of Science, 2009). Trust among scientists, and in the integrity of science as a discipline, is required to promote cooperative relationships and activities among researchers, such as collaborative work, publication, peer review, sharing data, replication of research results, teaching, and mentoring. Among scientists, there must be trust regarding the fidelity of data including accuracy, repeatability and in reporting of inherent uncertainties related to the data.

The bonds of trust between scientists and society are particularly important. Society has made great investments in support of science, and must trust that scientific results are an honest and accurate reflection of a scientist's work (National Academy of Science, 2009; 2017a). The public must be able to trust the scientific process to produce outcomes to inform public policy decisions (Obama, 2009). Scientists often serve on government advisory bodies and regulatory boards, give expert testimony to legislative committees or as major factor in criminal cases, products liability litigation, and malpractice lawsuits. Trust in scientific leadership is necessary to help the public gain acceptance of new technologies, and in consideration of risks and benefits of new technologies.

As with trust, there are many aspects of respect that bear on professional behavior: respect for individuals, the processes and products of science, equipment and their safe use, institutions, the profession, and the Earth. The progress of science is inherently adversarial, based on hyperbolic skepticism (“... never accept anything as true that I did not know evidently to be so; that is, carefully to avoid precipitous judgment and prejudice, and to include nothing more in my judgments than what presented itself to my mind with such clarity and distinctness that I would have no occasion to put it in doubt ..." (Descartes, 1637)); testing and refutation of hypotheses (e.g., Popper, 1959, 1963); and in the geosciences, inculcation of the scientific method (Gilbert, 1886) notes that [the researcher] "... must be fertile in the invention of hypotheses and ingenious in the application of tests ... The great investigator is primarily and preeminently the man who is rich in hypotheses ... The man who can produce but one, cherishes and champions that one as his own, and is blind to its faults. With such men, the testing of alternative hypotheses 
is accomplished only through controversy. Crucial observations are warped by prejudice, and the triumph of the truth is delayed" and Chamberlain's (1890) method of multiple working hypotheses wherein "the dangers of parental affection for a favorite theory can be circumvented". Respect for the heritage of the accepted practices of science is essential, particularly through scrutiny of ideas, methods and outcomes, and by challenging research findings based on the strength of evidence. However, in doing so, the integrity and dignity of individuals who conducted the research must be respected and protected. Appropriate professional behavior dictates that there is never cause to humiliate, denigrate, marginalize or abuse; ad hominem attacks on individuals and their personal attributes cannot be tolerated in the profession.

Responsibility is a key attribute of professionalism. Scientists will have professional responsibilities at many levels, to: science, the profession, colleagues, students, employers and employees, clients and end users, the public and humanity. Responsibility entails a personal duty or obligation to satisfactorily perform according to personal commitment or professional/social standards. A failure to act responsibly can lead to loss of personal or professional credibility, and possibly even legal actions. Responsible conduct of research is closely connected to professional behaviors in many ways, and this has been directly addressed in numerous reports (e.g., National Academy of Science, 2009 and 2017) and in scientific integrity policies defined by federal agencies (e.g., U.S. Department of the Interior http://www.doi.gov/ scientificintegrity/index.cfm, accessed on 6 November 2017 and U.S. Department of Agriculture http://www.usda.gov/documents/ usdascientific-integrity-policy-handbook.pdf accessed on 6 November 2017). The Singapore Statement on Research Integrity (2010) establishes four basic principles that also articulate professional responsibilities: Honesty in all aspects of research; Accountability in the conduct of research; Professional courtesy and fairness in working with others, and Good stewardship of research on behalf of others. The Cape Town Statement of the International Association for
Promoting Geoethics further articulates the responsibilities of geoscientists, ".... to improve both the quality of professional work and the credibility of geoscientists, to foster excellence in geosciences, to assure sustainable benefits for communities, as well as to protect local and global environments; all with the aim of creating and maintaining the conditions for the healthy and prosperous development of future generations" (Di Capua et al., 2017). One important professional behavior required of scientists is the need to self-police and report scientific misconduct, and there is a growing literature about how to address these issues (KeithSpeigel, 2010; Koocher and Keith-Speigel, 2010). Responsibilities to society have been articulated by AAAS (1998): “... if the U.S. is to respond effectively to the challenges of the 21st century, we must find ways to reorganize our science and technology enterprise to address tomorrow's needs and aspirations: maintaining global sustainability, improving human health, addressing economic disparities, understanding our place in the universe, promoting peace and security, and directing the products of technology toward the betterment of society, nationally and worldwide". These values were affirmed in the AAAS (2015) survey on social responsibility of scientists, engineers and health professionals. Geoscientists have a particularly important responsibility in communicating the nature of science and results of scientific research to the general public, particularly with regard to uncertainties in the areas of natural hazards and resources (e.g., Pollack, 2003; Lelliott et al., 2009; Lark, 2015; Lachner and Kirchengast, 2015; Bilham, 2015; Tinti et al., 2015).

\section{THE ROLE OF PROFESSIONAL SOCIETIES}

American Geosciences Institute (2016; Boland and Mogk, 2017) established Guidelines for Ethical Professional Conduct that articulates both personal and communal responsibilities of geoscientists. The American Geophysical Union (2017a) has updated its policies on Scientific Integrity and Professional Ethics that defines specific responsibilities of its members, and has developed related policies on conduct at meetings and publication ethics (American Geophys- 
ical Union Publication Ethics. https:/ / ethics.agu.org/home/publicationethics/, accessed 6 November 2017). The Geological Society of America Code of Conduct (https://www.geosociety.org/GSA/Members hip/Code_of_Conduct/GSA/Membership/Co de_of_Conduct.aspx?hkey=1a11cac9-2183-4e8f8cbd-3d930591fb56, accessed 6 November 2017) articulates responsibilities of members to the sciences and profession, students and colleagues, employer and employees, clients and end users, the public and humankind, and the environment and natural resources, and also defines principles of conduct for its members. The International Association for Promoting Geoethics (http://www.geoethics.org) has further articulated the fundamental values of geoethics in the Cape Town Statement of Geoethics (Di Capua et al., 2017). These are just a few examples of the many codes of conduct that have been developed by sister professional societies in the geosciences. The important point is that our discipline has made issues of geoethics and professionalism a high priority, and has set high standards for behaviors that are expected and accepted in the geoscience community.

\section{4. (UN)PROFESSIONAL BEHAVIORS: WHEN THINGS GO BAD}

To be blunt, we have a problem. Recent revelations in the news have exposed an epidemic of unprofessional behaviors in the form of sexual harassment and bullying across society. In academic settings, Libarkin (2017) reports 569 cases of academic sexual harassment (list updated November 9, 2017). These issues are not restricted to the academy. Recent reports also demonstrate a culture of male entitlement and sexual hostility in the United States Forest Service and National Park Services (Joyce, 2016). A shocking study by Clancy et al. (2014) reports on the results of a survey of trainees in field settings, and over $70 \%$ of the respondents reported that they had experienced or observed unwanted sexual remarks and over $20 \%$ reported they had personally experienced sexual assault (i.e. physical sexual harassment, unwanted sexual contact without consent).
The issues of sexual harassment and bullying in the geosciences have been directly addressed by Marín-Spiotta et al. (2016) and St. John et al. (2017). The Geological Society of America (2017) has proactively responded as they have instituted the Respectful, Inclusive, Scientific Events (RISE) to the Top program to ensure a safe and welcoming environment at its meetings. Similarly, the American Geophysical Union (2017b) has sponsored Safe AGU: Ethics, Response to Harassment, and Work-Climate Related Events at its annual meeting. Most significantly, the AGU Scientific Integrity and Professional Ethics policy (2017a) now specifically defines sexual harassment and bullying as a form of scientific misconduct with tough sanctions: "This policy takes a much stronger stance against harassment by including it in the definition of research misconduct and expanding its application to AGU members, staff, volunteers, and non-members participating in AGUsponsored programs and activities including AGU Honors and Awards, and governance" (Davidson et al., 2017; McPhadden et al., 2017). These issues are not restricted to the geosciences, and a much larger initiative is in progress to address sexual harassment across the STEM disciplines (e.g., National Academy of Sciences, Engineering and Medicine (2017b), workshops on Impacts of Sexual Harassment in Academia; American Geophysical Union (2016), workshop on Scientific Societies Speak Out Against Sexual Harassment (Wendel, 2016)). Sexual harassment and bullying have had devastating consequences for the individuals involved and for our profession. Too many colleagues, particularly women and those from underrepresented groups, have had to endure harassment, bullying, discrimination, and other offensive conducts, that have compromised their ability to work to their full potential, and all-too-often have driven these colleagues out of the field. In today's work climate, there is no excuse to not be aware; there is no justification for engaging in these behaviors; there is no place for these behaviors in the geoscience profession.

There are many other professional relations that have the potential for abuse of power and 
breach of trust. In any of these relations, it is important to recognize the inherent imbalance of power, the vulnerability of subordinates, and potential consequences for all parties involved. Consider the following relations:

- Mentoring; mentors are more than advisors, they play a prominent role in the mentee's development, supporting professional development, facilitating networking, creating opportunities. Mentors are in a position of trust, and yield great power over the professional prospects of their mentees.

- Letters of Recommendation; colleagues and students rely on letters of recommendation to pursue their career goals. Whitaker [2016] provides some practical advice on how to write a good letter of recommendation: decide whether you can write a good letter for the applicant; it's OK to say no; request as much information about the application before you begin writing; do some research about the job or appointment; provide ample time to write a good letter; be specific; avoid clichés and platitudes; organize the letter chronologically or thematically; be honest, original and genuine; and, follow through. Be aware of biases that you may reveal in your letters. Dutt et al. (2016) report: "Our results reveal that female applicants are only half as likely to receive excellent letters versus good letters compared to male applicants ... These results suggest that women are significantly less likely to receive excellent recommendation letters than their male counterparts at a critical juncture in their career".

- Publication Ethics also encompasses a variety of interpersonal interactions that can be included in professionalism: relations between editors, authors and reviewers and among co-authors raise issues of confidentiality, conflicts of interest, attribution and credit, and related issues of trust. The Committee on Publications Ethics (COPE: https://publicationethics.org/, accessed 6 November 2017) has detailed guidelines and resources related to these issues, the National Academy of Sciences (2009) addresses issues of authorship and allocation of credit, and professional societies have broadly disseminated their guidelines on publication (e.g., AGU's Scientific Ethics for Authors and Reviewers). Resnik (2011b) provides a nice summary of these issues in his essay "A Troubled Tradition, It's Time to Rebuild Trust Among Authors, Editors and Peer Reviewers".

- Data Rights and Policies; Data provide the factual basis for scientific work, and the integrity of research depends on all aspects of data management including the collection, use and sharing of data. All researchers have an interest in, and responsibility for, protecting the integrity of the research record. Data management presents many interesting questions that relate to professional behaviors: Who controls information? Is there (or should there be) an expectation of making information universally available? Who has the right to use information, and under what circumstances? How should sources be cited or provided attribution for data that may not be published or placed in a repository? Many types of data are of a proprietary nature and may have economic value. How scientists handle this type of data has implications for confidentiality, privacy, and conflict of interest. It is particularly important for all members of a research group, principal investigators, research staff, post-docs and students, to have a clear understanding of who has access and rights to publish data, and under what circumstances, to avoid potential interpersonal conflicts.

- Workplace safety; a culture of safety must be established in all work environments, in the lab, while traveling and in the field. Professional standards must be adhered to in areas such as safe handling and disposal of laboratory materials, safe operation of instruments and equipment, emergency response plans are in place, and safety education programs are in place (National Academy of Sciences, 2009). Field safety is a particular concern and has been addressed by Oliveri and Bohacs (2005) and Whitmeyer and Mogk (2013). Workplace safety standards will vary according to jurisdiction (e.g., national, state, institution) and it is incumbent on managers and workers to obtain any required licensures, certifications, 
and training, and to adhere to all relevant regulations to ensure the safety of workers, the workplace, and the environment.

- Contractor-client relations; Professionalism in relations between contractors and clients may be dictated to some extent by licensure and certification requirements, although these requirements may vary according to national or state jurisdictions. Practitioners need to be aware of issues related to competence, confidentiality, negligence, accurate representation of abilities, knowledge and expertise, and reporting standards regarding uncertainty. Geoscientists Canada (2014) have provided a comprehensive summary of a competency profile for professional geoscientists, and specific ethical guidelines for the profession.

- Serving as an expert witness; geoscientists may be called upon to serve as expert witnesses in civil or criminal cases. The role of the expert witness is to provide state-of-theart information pertaining to the issue, not to be an advocate for one side or the other. American Association for the Advancement of Science (AAAS) provides specific advice for Court Appointed Scientific Experts (CASE: https://www.aaas.org/page/courtappointed-scientific-experts-case, accessed 6 November 2017).

The principles of professionalism described in the first part of this contribution provide a good road map for navigating the complex and diverse interpersonal relations that contribute to the landscape of professional activities in the geosciences.

\section{CULTIVATING A CIVIL WORK ENVIRONMENT}

This is a good time for the geoscientists across the profession, in departments, institutions, professional societies and in companies, to ask the question: Is your department/workplace welcoming and inclusive for all people? Professional behaviors of individuals in aggregate contribute to the workplace "climate". Awareness of these issues is the first step. But action is also needed. The following is a list of topics that could be considered in depart- ment/company meetings, in formal training sessions, and in day-to-day interactions to help create a safe, inclusive and productive work environment.

- Civility: uncivil behavior in the workforce impacts workers' physical and mental health, productivity, and retention. Cortina et al. (2001) report on "... interpersonal mistreatment in the workplace by examining the incidence, targets, instigators, and impacts of incivility (e.g., disrespect, condescension, degradation) ... negative effects on job satisfaction, job withdrawal, and career salience. Uncivil workplace experiences were also associated with greater psychological distress". Does your department/company have an explicit statement of policy on inclusiveness, diversity, or intolerance? Some examples from geoscience departments at universities in the United States include: Baylor University where Members of the Baylor Geosciences Department, as part of the international geoscience community, are expected to abide by the AGU Scientific Integrity and Professional Ethics Policy; Boise State University has advertised a strong statement of inclusiveness on their departmental webpage; and, Colorado State University has developed a departmental values statement to "... represent our departmental culture, guide us as we interact as professional colleagues, influence how we make decisions, and frames a vision for our future".

- Diversity: Diversity is an opportunity, not an obstacle. Our profession is stronger if we embrace the diversity of people, interests, experiences and abilities. We can't afford to waste human capital. Is your department/program/workplace welcoming for all people? Are you proactively recruiting to broaden participation in the geosciences? The related topic of cultural sensitivity and literacy is increasingly important for geoscientists working in a globally interconnected world (see: InTeGrate module on Develop Cultural Competency: https://serc.carleton. edu/integrate/programs/diversity/dev_cult ural_comp.html, accessed 6 November 
2017), and has been identified as a key competency by the Summit on the Future of Undergraduate Geoscience Education (Employers' Workshop, May 2015, http://www.jsg.utexas.edu/events/futureof-geoscience-undergraduate-education/, accessed 6 November 2017).

- Implicit Bias: Implicit bias refers to the attitudes or stereotypes that affect our understanding, actions that are activated involuntarily without an individual's awareness or intentional control (American Women in Science - AWS: https://awis.siteym.com/?POLICYISSUES, accessed 6 November 2017). Implicit bias refers to attitudes and stereotypes that affect perception and judgment without our being aware of it. There is a large literature documenting evidence of gender bias in academic hiring (e.g., Moss-Racusin, 2012; Handley et al., 2015). Do you have mechanisms in place to detect and prevent implicit biases in your selection of candidates, hiring practices, and rewards and recognition policies? Related aspects of implicit bias include: The Halo Effect which is a cognitive bias where the overall impressions of an individual affect how we perceive other attributes of their character. For example, someone who appears to be physically attractive might also be considered to be a good leader, smart, funny, or well-liked. Anchoring Bias is a term used to describe the human tendency to rely too heavily on one trait (and often the first piece of information) when making decisions. Beware of first impressions! Confirmational bias is realized as people make decisions that confirm beliefs that are already developed. Thoughts and actions are commonly influenced by ingrained stereotypes. Aspects of confirmation bias include biased (or selective) searches for information, biased interpretation, and biased memories.

- Microaggressions are the casual degradation of any marginalized group through insults or dismissals, or other denigrating words or actions. Whether intentional or not, the impacts are real, cumulative, and can lead to diminished self-confidence and self-image and potentially can lead to men- tal health problems such as depression, anxiety and trauma. Jokes, comments, exclusion from group efforts have a cumulative negative affect on individuals (see Runyowa, 2015, Microaggressions Matter). Tolerance of these behaviors can lead to a hostile and even toxic work environment.

- Addressing Bias, Empowering Bystanders: There are well established strategies to address unconscious bias in professional life. A compilation of these strategies developed by numerous U.S. National Science Foundation ADVANCE programs can be found at the Virginia Tech ADVANCE Diversity and Equity portal (http://www.portal.advance .vt.edu/index.php/categories/diversity, accessed 6 November 2017). To promote safety and prevent hostile situations, policies and training can be adopted to empower bystanders to intervene. The University of New Hampshire Prevention Innovations Research Center has developed resources to help bystanders "identify behaviors on a continuum of violence, develop empathy or those who have experienced violence, practice safe and appropriate intervention skills, and commit to intervene before, during and after an incident occurs" (https:/ / cola.unh.edu/preventioninnovations-research-center accessed 6 November 2017). The National Sexual Violence Resource Center also has resources on Engaging Bystanders to Prevent Sexual Violence: A Guide for Preventionists (https://www.nsvrc.org/publications/nsvr c-publications-guides/engaging-

bystanders-prevent-sexual-violence-guide accessed, 6 November 2017).

This is a sampling of aspects of professional life that can have profound effects, either positive or negative, on individuals, the work environment and the profession.

\section{WHAT IS NEEDED: BE PREPARED, BE PROACTIVE}

Changes in the geoscience culture are needed at every level: personal, institutional, and as a profession. Geoscientists must do all they can to make sure their work environments adhere 
to the highest professional standards, so that all workers feel safe, welcomed and included in the profession. As a profession, we can't afford to lose human capital by driving people out due to unprofessional behaviors. Our workplaces, departments or companies, cannot afford to be exposed to liabilities for civil or even criminal charges when behaviors transgress from rude and boorish to illegal. An ounce of prevention is the best policy. Here are some suggestions about what can be done to promote professionalism in the geoscience workplace:

- Be explicit in addressing the issues of workplace climate with managers, coworkers, faculty, students and the public (Mogk, 2015). The cultural changes that are needed must be addressed openly and systemically from day-to-day interpersonal interactions to codified institutional or corporate polices.

- Develop a strategic plan that creates a collective vision for a healthy, successful science organization with clear targets and key performance indicators that directly address issues of discrimination, bias, harassment, bullying and other forms of abuse. Take a collective stand against harassment and publish antidiscrimination/harassment policies on webpages and in departmental brochures. Build a department that is inclusive, welcoming and safe.

- Be proactive and have policies in place to deal with professional issues; look for the warning signs, be aware of microaggressions and implicit bias;

- Build relations with the human resources department, affirmative action officer, campus security, counseling and psychological services, and other services to help prevent, and know how to respond to, disruptive behavioral issues if they should arise.

- Have an incident plan in place, know the policies and chains of communications so you can act quickly and appropriately if necessary. Protecting personal safety must be your highest priority, but protecting privacy and confidentiality is also important.
- Recognize that leadership comes from the top, and that senior colleagues (department heads, deans, managers) have a responsibility to set the professional expectations for the work group. Set the standard every day, every way.

- Make it easier to report abuse and harassment, and empower bystanders to act without fear of retribution or retaliation.

- Make safety in the work environment a day-to-day priority.

- In matters of harassment and bullying, no one can be neutral. Silence is not an option. The impacts on the individuals targeted by these behaviors will be devastating and irreversible. And, there will always be collateral damage to other workers and to the department or company. Put a stop to harassment and bullying before the situation causes irreparable damage.

- Performance review (and recommendations for promotion and rewards) should include aspects of professionalism. In the academy, annual reviews are typically limited to research productivity (published papers and grants), teaching (student credit hour production, course evaluations, number of undergraduate or graduate students supervised), and some minor component of service to department, institution, profession or community. I recommend that a fourth category be included in performance reviews: call it civility, collegiality, or citizenship, but recognition should be given to those who have embodied the highest standards of professional behavior. Those who have engaged unprofessional behaviors should be subject to lower performance reviews, required training or remediation, suspension, or even termination depending on the severity of the transgression.

- There are additional responsibilities of department chairs, section heads, and managers and supervisors: Keep the lines of communication open to everyone in your department; be aware of the climate in your department, and be proactive by intervening in interpersonal situations before they get out of hand; know the rules, what procedures are in place, and who to report to so that you can respond quickly and appro- 
priately when situations arise; realize that intent is irrelevant, and that actions have consequences whether intended or not.

- Finally, given the importance of geoethics and professionalism, it's fair to ask where and how should professional ethics be taught? Mogk et al. (2017) provide a detailed exploration of this question. The short answer is: everywhere. Good professional behavior should be modeled by faculty and working geologists day-to-day in all our work environments. Discussions of professionalism can be explicitly introduced into formal classes throughout the undergraduate and graduate geoscience curricula, and in research lab working groups. Corporations can institute in -house training sessions. Professional development workshops and short courses are routinely presented at meetings of professional societies, and students, peers, and colleagues should be encouraged to attend. Professional behaviors are learned behaviors. All members of the geoscience profession have an interest in, and responsibility for, establishing and reinforcing the highest ethical standards of the profession.

\section{CLOSING THOUGHTS}

Most working scientists are knowledgeable about what is meant by responsible conduct of research. We are less conversant about responsible conduct of scientists. Few geoscientists have the training, knowledge or interest to deal effectively with unprofessional, interpersonal behaviors as they arise. We have a lot to learn from our colleagues in the social sciences. The purpose of this contribution is to introduce some fundamental principles that inform professionalism, and how we can best work together when attending meetings, or when at work in the office, field or laboratory. As a discipline, we cannot afford to ignore the causes and consequences of interpersonal conflicts that may arise in the workplace, particularly with respect to discrimination, sexual harassment and bullying. Hopefully, this brief introduction will provide the incentive for the geoscience community to be proactive in our personal lives and professional situations, and to make sure that all our colleagues are treated with the dignity and respect that they deserve. Reflect personally, start the conversation among colleagues, take appropriate actions to make sure that high standards of professional behaviors are established and expected, so that we all will have a safe, welcoming and inclusive work environment. We are all better when we work together.

\section{ACKNOWLEDGEMENTS}

Work by the author on professionalism was originally supported by the NSF Ethics Education in Science and Engineering (EESE) program, grant number NSF 133874 to develop the Teaching Geoethics Across the Geoscience Curriculum website. Subsequent participation by the author in the AGI Committee to revise the Code of Conduct for geoscientists, AGU Ethics Task Force, GSA committee on Supporting Success for Women in the Geosciences, and IAPG sponsored events at IGC meetings contributed greatly to the development of the ideas presented. Reviews by Giuseppe di Capua and anonymous reviewers greatly improved the clarity of this contribution. More extensive resources on Geoethics can be found at the associated website: https://serc.carleton.edu/74990. Any opinions, findings, and conclusions or recommendations expressed in this material are those of the author and do not necessarily reflect the views of the National Science Foundation or professional societies referred to in this contribution

\section{REFERENCES}

American Association for the Advancement of Science, Board of Directors (1998). A Framework for Federal Science Policy, (cited at Resources for Research Ethics Education. http://research-ethics.net/topics/socialresponsibility/), accessed 6 November 2017.

American Association for the Advancement of Science (2015). Investigating the Perceived Social Responsibilities of Scientists, Engineers and Health Professionals. https://mcmprodaaas.s3.amazonaws.com/ s3fspublic/AAAS\%20Social\%20Responsibil ity\%20Questionnaire\%20Report_A\%20Preli minary\%20Inquiry.pdf, accessed 6 November 2017. 
American Geophysical Union (2016). Scientific Societies Speak Out Against Sexual Harassment. https://news.agu.org/pressrelease/scientific-societies-speak-outagainst-sexual-harassment, accessed 6 November 2017.

American Geophysical Union (2017a). AGU Scientific Integrity and Professional Ethics, https://ethics.agu.org/files/2013/03/Scien tific-Integrity-and-Professional-Ethics.pdf, accessed 6 November 2017.

American Geophysical Union (2017b). Safe AGU: Ethics, Response to Harassment, and Work-Climate Related Events, http://fallmeeting.agu.org/2017/safeagu/, accessed 6 November 2017.

American Geosciences Institute (2016). AGI Guidelines for Ethical Professional Conduct. https://www.americangeosciences.org/com munity/agi-guidelines-ethical-professionalconduct, accessed 6 November 2017.

Bilham R. (2015). Ethics of the maximum credible earthquake. In: Wyss M. and Peppoloni S. (eds.), Geoethics: Ethical Challenges and Case Studies in Earth Sciences, 120-140, Elsevier, Amsterdam.

Boland M. and Mogk D.W. (2017). The American Geosciences Institute Guidelines for Ethical Professional Conduct. In: Gundersen L. (ed), Scientific Integrity and Ethics in the Geosciences, American Geophysical Union/Wiley, ISBN: 978-1-119-06778-8.

Chamberlain T.C. (1890). The method of multiple working hypotheses. Science, 15: 92-96 (reprinted 1965, 148:754-759).

Clancy K.B.H., Nelson R.G., Rutherford J.N., Hinde, K. (2014). Survey of Academic Field Experiences (SAFE): Trainees Report Harassment and Assault. PLoS ONE 9(7): e102172. doi:10.1371/journal.pone.0102172.

Cortina L.M., Magley V.J., Williams J.H., and Langhout R.D. (2001). Incivility in the Workplace: Incidence and Impact, Jour. Occupational Health Psychology, 6(1):64-80.

Davidson E., Bell R., Leinen M. (2017). A Revised Ethics Policy: Setting the Bar High to End Harassment in the Sciences, American Geophysical Union From the Prow. http://fromtheprow.agu.org/setting-thebar-high-to-end-harassment-in-thesciences/, accessed 6 November 2017.
Descartes R. (1637). Discourse on Method and Meditations on First Philosophy, translated by Donald A. Cress, Hackett Publishing Co., Indianapolis.

Di Capua G., Peppoloni S., and Bobrowsky P. (2017). The Cape Town Statement on Geoethics. Annals of Geophysics, 60, Fast Track 7, doi: 10.4401/ag-7553.

Dutt K., Pfaff D.L., Bernstein A.F., Dillard J.S., and Block C.J. (2016). Gender differences in recommendation letters for postdoctoral fellowships in geoscience. Nature Geoscience, 9:805-808.

Geological Society of America (2017). GSA Meetings RISE to the Top, http://www.geosociety.org/GSA/Events/E ventConductCode/GSA/Events/Conductintro.aspx, accessed 6 November 2017.

Geoscientists Canada (2014). Competency Profile for Professional Geoscientists at Entry to Practice, https://geoscientistscanada.ca/wpcontent/uploads/2015/07/CompetencyProfile-for-Professional-Geoscientistsat-Entryto-Practice-Combined-Doc.pdf, accessed 6 November 2017.

Gilbert G.K. (1886). The inculcation of scientific c method by example, with an illustration drawn from the Quaternary geology of Utah. American Journal of Science, 31: 284299.

Handley I.M., Brown E.R., Moss-Rausin C.A., and Smith J.L. (2015). Quality of evidence revealing subtle gender biases in science is in the eye of the beholder. PNAS, 112(43):13201-13206.

Joyce K. (2016). Out Here, No One Can Hear You Scream. Huffington Post HighLine, http:/ / highline.huffingtonpost.com/article s/en/park-rangers/, accessed 6 November 2017.

Keith-Spiegel P., Sieber J., and Kocher G.P. (2010). Responding to Research Wrongdoing: A User-Friendly Guide. http://www.ethicsresearch.com/images/R RW_11-10.pdf, accessed 6 November 2017.

Koocher G.P. and Keith-Spiegel P. (2010). Peers nip misconduct in the bud. Nature, 466:438440.

Lachner B.C. and Kirchengast G. (2015). Communication and perception of uncertainty via graphics in disciplinary and interdiscip- 
linary climate change research. Geophysical Research Abstracts, 17, EGU2015-2240, 2015 EGU General Assembly.

Lark M. (2015). Map scale and the communication of uncertainty, Geophysical Research Abstracts, 17, EGU2015-1953, 2015 EGU General Assembly.

Lelliott M., Cave M., Wealthall G. (2009). A structured approach to the measurement of uncertainty in 3D geological models. Quarterly Journal of Engineering Geology and Hydrogeology, 42(1). 95-105.

Libarkin J. (2017). Not a Fluke: That Case of Academic Sexual Harassment, Sexual Assault, Sexual Misconduct, Stalking, Violations of Dating Policies, Violations of Campus Pornography Policies, and Similar Violation is not an Isolated Incident, https:/ / geocognitionresearchlaboratory.wo rdpress.com/2016/02/03/not-a-fluke-thatcase-of-sexual-harassment-is-not-anisolated-incident/, accessed 9 November 2017.

Marín-Spiotta E., Schneider B., and Holmes M.A. (2016). Steps to building a notolerance culture for sexual harassment, Eos, 97, doi: 10.1029/2016EO044859.

McPhaden M.J., Gundersen L., and Williams B.M. (2017). AGU revises its integrity and ethics policy, Eos, 98, doi: 10.1029/2017EO082469.

Mogk D.W. (2015). Be explicit: Geoscience program design to prepare the next generation of geoscientists. Amer. Geophys. Union Fall Meeting, San Francisco, CA. Paper ED 21E07.

Mogk D.W., Geissman J.W., and Bruckner M.Z. (2017). Teaching Geoethics Across the Geoscience Curriculum: Why, When, What, How, and Where? In: Gundersen L. (ed.). Scientific Integrity and Ethics: With Applications to the Geosciences. Special Publication American Geophysical Union, John Wiley and Sons, Inc., ISBN: 978-1-119-06778-8.

National Academy of Science (2009). On Being a Scientist: A guide to responsible conduct of research (3rd ed.), National Academy Press, Washington D.C., 82 pp.

National Academies of Sciences, Engineering, and Medicine (2017a). Fostering Integrity in Research. The National Academies Press,
Washington D.C., https://www.nap.edu/ catalog/21896/fostering-integrity-in-research, accessed 18 December 2017.

National Academies of Sciences, Engineering, and Medicine (2017b). Impacts of Sexual Harassment in Academia. http:/ / sites.nationalacademies.org/PGA/c wsem/shstudy/index.htm, accessed 6 November 2017.

Obama, B. (2009), Scientific Integrity, Memorandum for the Heads of Executive Departments and Agencies 3-9-09, https://obamawhitehouse.archives.gov/th e-press-office/memorandum-headsexecutive-departments-and-agencies-3-9-09, accessed 6 November 2017.

Oliveri S.R. and Bohacs K. (2005). Field Safety in Uncontrolled Environments. AAGG/DEG and ExxonMobil, 150 pp.

Pollack H.N. (2003). Uncertain Science... Uncertain World, Cambridge University Press, $241 \mathrm{pp}$.

Popper K.R. (1959). The Logic of Scientific Discovery, London: Routledge.

Popper K.R. (1963). Conjectures and Refutations: The Growth of Scientific Knowledge, London: Routledge.

Resnik D. (2011a). Scientific Research and the Public Trust. Science Engineering Ethics, 17(3): 399-409.

Resnik D. (2011b). A Troubled Tradition It's Time to Rebuild Trust Among Authors, Editors, and Peer Reviewers. Scientific American, 99(1):24-27.

Ross-Macusin C.A., Dovidio J.F., Brescoll V.L., Graham M.J., and Handelsman J. (2012). Science faculty's subtle gender biases favor male students, PNAS, 109(41):16474-16479.

Runyowa S. (2015). Microaggressions Matter. Atlantic Magazine, September 18, 2015, https://www.theatlantic.com/politics/arch ive/2015/09/ microaggressionsmatter/406090/, accessed 6 November 2017.

St. John K., Riggs E., and Mogk D. (2016). Sexual Harassment in the Sciences: A Call to Geoscience Faculty and Researchers to Respond. Jour. of Geoscience Education, 64:255-257.

Singapore Statement on Research Integrity (2010). 2nd World Conference on Research 
Integrity, Singapore, 21-24 July 2010, www.singaporestatment.org, accessed 6 November 2017.

Tinti S., Armigliato A., Pagnoni G., and Zaniboni F. (2015). Geoethical and social aspects of warning for low-frequency and largeimpact events like tsunamis. In: Wyss $\mathrm{M}$. and Peppoloni S. (eds.), Geoethics: Ethical Challenges and Case Studies in Earth Sciences, 176-192, Elsevier, Amsterdam

Wendel J. (2016). AGU-sponsored workshop targets sexual harassment in the sciences. Eos, 97, doi: 10.1029/2016EO059651.

Whitaker M. (2016). Tips for Writing Recommendation Letters, Inside Higher Education, https://www.insidehighered.com/ advice/2016/12/02/how-write-strongerletters-recommendation-studentsessay?utm_source=Inside+Higher+ Ed\&utm_campaign=af31fc1fbcDNU20161202\&utm_medium=email\&utm_ term=0_1fcbc04421-af31fc1fbc-

198468613\&mc_cid=af31fc1fbc\&mc_eid=b4 ec990e8e, accessed 6 November 2017

Whitmeyer S. and Mogk D.W. (2013). Safety and Liability Issues Related to Field Trips and Field Courses. Eos, 94, 40, doi: 10.1002/2013EO400002

* Further correspondence with the author can be sent to: David Mogk, Dept. of Earth Sciences, Montana State University, Bozeman, MT 59717 